\title{
PENGELUARAN KAYU SISTEM KABEL LAYANG GAYA GRAVITASI DENGAN KERETA PENGANGKUT KAYU BER-REM KITO PADA DAERAH BERTOPOGRAFI SULIT DI SUKABUMI.
}

\section{(Wood Extraction by Gravity Skyline System Using Locked Carriage of Kito Model on Heavy Terrain in Sukabumi)}

\author{
Oleh/By: \\ Wesman Endom \\ Pusat Litbang Hasil Hutan, Jl. Gunung Batu No. 5 Bogor Tlp/Fax: 8633378/8633413 \\ Diterima 30 Mei 2007; disetujui 26 Mei 2008
}

\begin{abstract}
Experiment of pine wood extraction usng skyline cable technology of gravity (GSS = Gravity Skyline system) wa done at Kampung Cigalasar, Bojongkalong, Sub district Nyalindung, Sukabumi, in the pine forest which stands are of diameter ranged between $24-45 \mathrm{~cm}$, that was being tapped.

The downbill extraction, with $\pm 350 \mathrm{~m}$ distance, showed that this technology is quite good. However, there are stiill several constaints that need improvement, i.e.:

a). Some beams to bave stepping space, to make it easy when installing or repairing

b). the beams to have stepping space, to make it easy when installing or repairing

c). The cable needs to be installed in a straight line, so that the cable is easily removed

d). The safety precautions need to be implemented in re installing the cable, in installing wood carrier, in ligbtening wood load, in using proper man power.

The productivity of GSS are $5-9,104.3 \mathrm{~m} 3 / \mathrm{hm} /$ hour with average of $7.033 \mathrm{~m} 3 / \mathrm{hm} /$ hour. Cost of wood extraction was about $\mathrm{R} p .48 .668 /$ bour of Rp. $6.920 / \mathrm{m} 3$. With investment loot of $\mathrm{R} p .20$ million and senting price of $\mathrm{R} p .10,500 / \mathrm{m} 3 / \mathrm{bm}$, it is calculated that after 6 years the NPU can be seached $(\mathrm{R} p 14,455,241)$ and the IRR is $31.9 \%$
\end{abstract}

Key words: System kabel layang,, productivity, operational cost, gravity

\section{ABSTRAK}

Uji coba pengeluaran kayu pinus dengan teknologi kabel layang menggunakan gaya gravitasi dan dikenal dengan istilah GSS, dicoba dilakukan di Kampung Cigalasar, Desa Bojongkalong, Kecamatan Nyalindung, Sukabumi, pada tegakan pinus berdiameter antara $24-45 \mathrm{~cm}$ yang saat ini masih disadap getahnya.

Hasil uji coba pengeluaran kayu ke arah bawah lereng dengan bentangan alam $\pm 350 \mathrm{~m}$ memperlihatkan bahwa teknologi ini cukup baik dan produktif. Sejumlah hambatan yang dialami dan dinilai masih perlu perbaikannya antara lain perlunya penyangga di beberapa tempat agar muatan kayu tidak menyentuh pemukaan tanah akibat panjangnya bentangan kabel, tiang penyangga dilengkapi dengan pijakan panjat agar mudah saat melakukan pemasangan atau bila terjadi sesuatu perbaikan, pemasangan jalur kabel agar berada pada satu garis lurus sehingga kabel mudah lepas dari penyangga, hati-hati dalam saat memasang posisi kereta angkut kayu, hati-hati dalam memasang 
ulang kabel tanpa ujung, pengikatan kayu yang praktis dan kuat, penggunaan tenaga yang memadai dan model pengunci kabel penarik lebih kuat.

Produktivitas kerja GSS sebesar 5-9.104,3 $\mathrm{m}^{3} . \mathrm{hm} /$ jam dengan rata-rata 7,033 $\mathrm{m}^{3} . \mathrm{hm} / \mathrm{jam}$ dan biaya pengeluaran kayu sebesar Rp 48.668/jam atau Rp $6.920 / \mathrm{m}^{3}$. Dengan investasi sebesar Rp 20 juta dan dapat disewakan dengan biaya sewa sebesar Rp $10.500 / \mathrm{m}^{3} / \mathrm{hm}$, maka setelah 6 tahun dapat diperoleh nilai NPV sebesar Rp 14.445.241 dan IRR sebesar 31,9\%.

Kata kunci: Sistem kabel layang, produktivitas, biaya operasional, gaya gravitasi.

\section{PENDAHULUAN}

Kabupaten Sukabumi merupakan salah satu wilayah di Jawa Barat yang memiliki hutan produksi rimba dan hutan jati cukup potensial. Luas kawasannya meliputi $105.348,27$ ha yang terbagi atas hutan produksi $65.126,16 \mathrm{ha}$; hutan lindung $12.372,00$ ha, hutan suaka alam 24.769,36 ha dan hutan cadangan 3.080,75 ha. (Anonim 1993). Secara umum kelas perusahaan hutan rimba, berada di wilayah berbukit dengan jenis pohon yang dikelola antara lain pinus, mahoni, puspa, agathis dan rasamala. Untuk wilayah-wilayah hutan yang lerengnya dikategorikan curam, curah hujan tinggi serta jenis tanahnya peka erosi, dimasukan ke dalam katageori hutan lindung.

Hingga saat ini, hutan produksi rimba banyak yang sudah menjadi tegakan dengan diameter cukup besar-besar. Namun, karena sulitnya akses ke daerah itu maka pemanfaatan tegakan utamanya dari jenis pinus, baru sebatas pengambilan getahnya dengan cara disadap. Padahal, kebutuhan akan kayu untuk berbagai industri yang memanfaatkan kayu pinus cukup tinggi, seperti industri korek api, mebel, pulp dan kertas, serta peti kemas untuk tujuan ekspor.

Salah satu lokasi dari kelas perusahaan hutan pinus yang cukup potensial namun memiliki akses rendah terletak di Gunung Gadog, Kampung Cigalasar, Kecamatan Nyalindung, Sukabumi. Diperkirakan potensi kayunya mencapai volume sebanyak $5.000 \mathrm{~m}^{3}$. Untuk mengeluarkan kayu tersebut, penggunaan cara manual (dipikul/ digotong) di samping sulit dan berisiko tinggi, juga tidak efektif dan efisien karena sangat terbatasnya kemampuan tenaga manusia. Dengan motor roda dua yang sekalipun kini sudah menjadi model, juga sulit untuk dilakukan karena sangat rendahnya akses. Di samping itu bila turun hujan, jalannya sangat licin dan lengket sehingga sangat membahayakan.

Dengan kondisi seperti itu, teknologi kabel layang merupakan pilihan yang cukup dapat diandalkan. Namun, mengingat pengeluaran kayu dengan sistem ini pelaksanaannya juga tidak mudah dan berisiko tinggi, maka penyelenggaraannya perlu memperhatikan beberapa hal berikut : (1) besarnya volume per hektar yang akan dikeluarkan pada sebuah lokasi penebangan, (2) kondisi lapangan penebangan kayu, (3) ukuran kayu, (4) jarak pengeluaran kayu dan nilai nilai kayu serta kondisi cuaca dan (5) tenaga kerja (Binkley dkk. (1968) dalam Dulsalam, 2006)

Dalam penelitian ini dicoba dikaji penggunaan teknologi kabel layang dengan memafaatkan gaya beratnya sendiri atau lebih sering dikenal dengan istilah Gravity Skyline System (GSS ), yaitu suatu cara dimana kayu dikeluarkan melalui penggunaan gantungan kereta angkut kayu (carriage) yang meluncur setelah dikunci pada kabel tanpa ujung (endless cable) pada kemiringan lapangan menurun sekitar 40\%. Kemiringan lapangan ini cukup efektif untuk dapat dipakai mengeluarkan kayu pada wilayah yang aksesibilitasnya rendah 
dengan cara diluncurkan melalui kabel yang dihubungkan dengan alat pengereman di bagian atasnya.

\section{METODE PENELITIAN}

\section{A. Lokasi Penelitian}

Penelitian dilakukan pada bulan Oktober - Nopember 2007 di kawasan hutan wilayah KPH Sukabumi Propinsi Jawa Barat. Lokasi tempat uji coba ini berada di kampung Cigalasar Desa Bojong Kalong, berada pada jarak $\pm 350 \mathrm{~m}$ dari hutan. Dari tempat ini karena lapangannya menaik maka kemudian kayu diangkut dengan teknologi kabel layang lain menggunakan mesin dan tidak menjadi bagian dalam pembahasan pada penelitian ini.

\section{B. Bahan dan Alat}

1. Perangkat GSS termasuk kabel utama dan kabel tanpa ujung (endless cable)

2. Kereta angkut kayu, seperangkat kunci dan alat bantu lain di lapangan

3. Solar dan oli

4. Tally sheet untuk pencatatan data

5. Kamera

6. Stopwatch, meteran, tambang, kompas dan sarung tangan

\section{Prosedur Kerja}

Alat yang digunakan untuk pengerem kabel tanpa ujung berfungsi untuk menghentikan peluncuran kereta angkutan kayu dimana saja diperlukan, secara cepat ataupun perlahan, utamanya setelah akan mencapai tempat pengumpulan kayu. Dengan demikian kereta muatan yang meluncur dapat terkendali yang dengan perlahan berhenti tepat di tempat pembongkaran berada sehingga tidak membahayakan petugas.

Tahapan kegiatan dalam pengeluaran kayu yang dilakukan secara garis besar dikerjakan sebagai berikut:

a. Survei untuk memilih lokasi pemasangan jalur kabel menggunakan kompas.

b. Pembersihan dan penebangan dahan pepohonan di jalur kabel terpilih.

c. Pengeluaran, penguluran dan pemasangan kabel utama, dan kabel penarik (lifting) dan kabel penarik (endless) dari gulungan.

d. Pengencangan kabel utama dengan tirfor dan penyambungan kabel endless.

e. Penunjukkan TPn sementara.

f. Pemasangan panggung atas dan panggung bawah

g. Pemasangan dan pelepasan penarik kayu (carriage) dan rantai pengikat kayu.

Sebelum dioperasikan terlebih dahulu diperiksa kesiapan semua sistem kerja alat termasuk jaringan kabel utama maupun kabel penarik, penahan tiang, katrol, sistem rem, serta tenaga kerja dan pembagian tugas. 


\section{Analisis Data}

1. Menghitung produktivitas kerja pemuatan, pembongkaran dan pengumpulan.

$$
\mathrm{PK}=\frac{\mathrm{V} \times \mathrm{J}}{\mathrm{W}}
$$

di mana $\mathrm{PK}=$ Produktivitas kerja $\left(\mathrm{m}^{3} \mathrm{~m} /\right.$ menit $) ; \mathrm{V}=$ Volume muat kayu $\left(\mathrm{m}^{3}\right) ; \mathrm{W}=$ Waktu kerja efektif (menit) dan J = Jarak sarad atau muat $(\mathrm{m})$.

2. Menghitung volume kayu

$$
\mathrm{V}=0,25 \times 3,14(\mathrm{Dp}+\mathrm{Du})^{2} / 2 \times \mathrm{L} \ldots \ldots .(2)
$$

dimana $\mathrm{V}=$ Volume kayu $\left(\mathrm{m}^{3}\right) ; \mathrm{Dp}=$ Diameter pangkal $(\mathrm{cm})$;

$\mathrm{Du}=$ Diameter ujung $(\mathrm{cm})$ dan $\mathrm{L}=$ Panjang $(\mathrm{m})$

3. Analisis biaya

Analisa biaya dilakukan dengan mengikuti cara perhitungan Soenarso (1965), yang pada dasarnya biaya setiap tahunan dipilah dalam 3 bagian yakni (1) biaya tetap, (2) biaya tidak tetap dan (3) biaya persiapan.

- Biaya tetap terdiri dari biaya penghapusan alat dan bunga serta biaya perawatan. Dalam biaya ini juga dimasukan pajak dan asuransi. Perumusan yang digunakan disajikan dalam rumus di bawah.

- Biaya tidak tetap terdiri dari biaya penggunaan bahan bakar (solar, bensin, oli, gemuk dan upah pekerja termasuk operator.

- Biaya persiapan. Misal pemasangan jaringan kabel, yang dihitung dengan disesuaikan dengan tingkat kesulitan lapangan.

Rumus yang dipakai untuk menghitung biaya penghapusan dan bunga per tahun:

$$
\underline{\mathrm{M} \mathrm{R}}+(\mathrm{M}-\mathrm{R}) \times \underline{0.0 \mathrm{p}} \times \underline{(\mathrm{n}+1)}+\mathrm{R} \times 0.0 \mathrm{p}
$$

$$
\begin{aligned}
& \text { dimana: } \mathrm{M}=\text { modal yang dimasukan } \\
& \mathrm{R} \text { = harga residu (rongsokan) } \\
& \mathrm{n} \quad=\text { jumlah tahun dimana modal dihapuskan } \\
& \mathrm{p} \quad=\text { bunga } \\
& \underline{\mathrm{M} \mathrm{R}}=\text { penghapusan modal secara garis lurus (straight line) } \\
& \mathrm{n} \\
& (M-R) \times \underline{0.0 p} \times \underline{(n+1)}=\text { bunga rata-rata } \\
& 2 \mathrm{n} \\
& \mathrm{R} \times 0.0 \mathrm{p}=\text { bunga harga likuidasi }
\end{aligned}
$$

$\underline{\text { Harga alat }(\mathrm{Rp}) \times 0,1=\text { biaya perawatan }}$ 1000 jam

$\underline{\mathrm{H} \times 0,6 \times 2 \%}=$ pajak

1000 jam

$\underline{\mathrm{H} \times 0,6 \times 3 \%}=$ asuransi 1000 jam 
Biaya pengeluaran kayu $(\mathrm{BE})=$ Biaya tetap + Biaya tidak tetap + Biaya persiapan.

Biaya pemakaian dalam setiap $\mathrm{m}^{3}=\mathrm{BE} /$ Produktivitas kerja

Selain itu dicoba dianalisis kelayakan finansial dari pendapatan sebagai hasil penyewaan alat untuk jangka pengembalian 6 tahun (IRR dan NPV) dengan asumsi sebagai berikut:

- waktu kerja per tahun 200 hari a 6 jam per hari, bunga yang dihitung $16 \%$ per tahun

- asumsi hasil menyewakan alat $=\mathrm{Rp} 17.500 / \mathrm{hm} / \mathrm{m} 3$, kemampuan pengeluaran kayu $48 \mathrm{~m} 3 /$ hari atau $8 \mathrm{~m}^{3} /$ jam sedang biaya lainnya sama seperti pada perhitungan di atas.

\section{HASIL DAN PEMBAHASAN}

\section{A. Hasil Kegiatan}

\section{Gambaran lokasi uji coba}

Penggunaan lahan menuju ke lokasi antara lain pemukiman, sawah dan kebun/tegalan dengan kemiringan lapangan pada jalur kabel sekitar 40\%, sehingga cukup memiliki daya untuk dapat meluncurkan muatan kayu melalui gaya beratnya.

Untuk pemuatan kayu digunakan kereta angkut kayu yang pengikatannya dilakukan di atas alat bantu yang telah disiapkan, biasa disebut panggung muat kayu. Panggung ini diperlukan mengingat cukup beratnya menahan beban dari kayu yang akan diangkut selama proses pengikatan. Untuk keperluan ini dibuatlah alat tersebut dan untuk penempatannya dipilih di areal yang cukup datar, agak luas dan dekat dengan ujung kabel. Agar kayu yang diluncurkan dapat berhenti di berbagai tempat sesuai yang diperlukan, maka dalam peluncuran kayu digunakan rem yang berada sekitar 8 meter dari panggung, dengan penempatan sedemikian rupa sehingga dapat melihat ke kedua arah dengan jelas yakni ke tempat pemuatan dan ke tempat bongkar kayu yang jaraknya sejauh $\pm 350 \mathrm{~m}$.

Dapat dilihat cukup jelas bagaimana kompleksnya pengeluaran kayu yang harus melalui kebun dan pesawahan serta wilayah pemukiman (lihat Gambar 1). Kendala lain yang dihadapi ialah adanya jalur kabel listrik yang menguhubungkan antara perumahan dan itu harus dapat dihindari agar tidak membahayakan. Selain itu, posisi tail tree dan tempat untuk bongkar muat kayu berada di lintasan jalan kampung, sehingga untuk menghindari hal-hal yang tidak diinginkan petugas segera akan memberitahukan kepada para pejalan kaki untuk berhenti dahulu sesaat hingga kegiatan peluncuran berhenti dan kayunya segera dibongkar.

\section{Operasi penggunaan GSS}

Setelah jalur kabel untuk sistem GSS terpasang, hasil beberapa uji coba menemukan beberapa hambatan yang harus diantisipasi ke depan yaitu (a) agar muatan tidak menyentuh pematang dan permukaan sawah (b) kereta angkutan kayu tidak terhalangi dahan atau batang pohon dan (c) kabel utama tidak kendor.

Sebagai upaya untuk lebih mengencangkan kabel pada tail tree yang sudah ditunjuk, kabel utama kemudian dipindahkan ke pohon lain yang ada di bagian lebih atas sejauh lebih dari $50 \mathrm{~m}$ dari pohon tail tree awal. Namun, pemindahan tail tree tersebut belum sepenuhnya 
berhasil mengatasi muatan yang masih menyentuh tanah, akibat cukup panjangnya bentangan kabel. Untuk itu perlu dipasang penyangga kabel. Penyangga ini kemudian dipasang pada pohon pinus yang berada tidak jauh dari lokasi dimana muatan menyentuh permukaan tanah. Sayangnya, posisi penyangga masih belum sepenuhnya optimal, karena letak pohon menyerong. Kendati demikian setelah dipasang penyangga tersebut, pengeluaran kayu dapat berjalan cukup mulus (lihat Gambar 2).

Kendala lain yang masih ada adalah terjadi pada pengunci sistem baud kereta angkut kayu. Model alat ini ternyata ulirnya cepat aus akibat menahan beban dan akibat sering dibukapasang baudnya, sehingga mur tidak dapat mengunci dengan baik. Oleh karena itu, model kereta angkut kayu ini dirombak dan diganti dengan pengunci menggunakan sistem kito. Lebih jelasnya untuk mengetahui kedua model carriage tersebut disajikan pada Gambar 3.

Hasil uji coba pengeluaran kayu dengan menggunakan teknologi kabel layang GSS disajikan pada Tabel 1.

Dari Tabel 1 dapat diketahui bahwa pengeluaran kayu dengan teknologi kabel layang gaya gravitasi (GSS) memerlukan waktu angkut berkisar antara 1,05 -9,67 menit. Jauhnya kisaran tersebut umumnya terjadi disebabkan jarak dan kesulitan saat membuka muatan sewaktu menggunakan kereta kayu model lama, karena untuk mencopot muatan kayu harus diangkat ke atas terlebih dahulu sementara muatan kayu tersebut cukup berat. Pembongkaran kayu terkadang memerlukan tenaga hingga 5 orang dan untuk itu kemudian dibangun panggung bawah dengan menggunakan potongan kayu yang telah diangkut. Selain itu kesulitan lain terjadi karena kesalahan melilitkan rantai pengikat, sehingga untuk membukanya memerlukan banyak waktu dan atau muatan membentur tanah sehingga lepas. Penambahan waktu juga terjadi karena tidak otomatis setelah bendera kuning dikibarkan yang artinya peluncuran kayu dapat dilakukan, tetapi tidak segera meluncur karena operator GSS tidak melihatnya sehingga juga menambah waktu angkut. Setelah dihitung produktivitas rata-rata pengeluaran kayu dengan sistem GSS adalah $7,033 \mathrm{~m}^{3} \cdot \mathrm{hm} / \mathrm{jam}$.

Menurut Basari dkk (1998) produktivitas kerja ekstraksi kayu dengan sistem kabel layang gaya berat ber-rem yang pernah dicoba rata-rata $0,22 \mathrm{~m}^{3} /$ rit atau rata-rata $2,27 \mathrm{~m}^{3} /$ jam. Sementara ukuran kayunya yang diekstraksi rata-rata $22,25 \mathrm{~cm}$ dengan panjang rata-rata 2,27 $\mathrm{m}$. Lebih tingginya produktivitas yang dicapai dari hasil uji coba yang dilakukan diyakini karena kereta kayu yang dipakai dengan menggunakan sistem rem kito lebih efektif dan praktis.

Memperhatikan nilai capaian yang diuji coba dibanding dengan capaian sebelumnya jelas sekali terlihat peningkatannya dari 2,27 menjadi $7,033 \mathrm{~m}^{3} \cdot \mathrm{hm} / \mathrm{jam}$. Ini berarti meningkat hampir 3,5 kalinya. 
Tabel1. Hasil uji coba pengeluaran kayu dengan sistem GSS

Table 1. Trial test of logs extraction using GSS system

\begin{tabular}{|c|c|c|c|c|c|c|}
\hline No & $\mathrm{N}$ & $\begin{array}{l}\text { Diameter } \\
\quad(\mathrm{cm})\end{array}$ & $\begin{array}{l}\text { Panjang } \\
\text { (Length) } \\
(\mathrm{cm})\end{array}$ & $\begin{array}{l}\text { Jarak } \\
\text { (Distance) } \\
\text { (m) }\end{array}$ & $\begin{array}{l}\text { Waktu } \\
\text { (Time) }\end{array}$ & $\begin{array}{l}\text { Produktivitas } \\
\text { (Productivity) } \\
\left(\mathrm{m}^{3} \cdot \mathrm{hm} / \mathrm{jam}\right)\end{array}$ \\
\hline 1 & 3 & 26 & 130 & 35 & 1.04 & 1.393 \\
\hline 2 & 2 & 28 & 130 & 30 & 1.05 & 1.372 \\
\hline 3 & 3 & 25 & 130 & 200 & 9.1 & 0.841 \\
\hline 4 & 3 & 24 & 130 & 50 & 4 & 0.441 \\
\hline 5 & 3 & 30 & 130 & 50 & 0.53 & 5.199 \\
\hline 6 & 2 & 30 & 130 & 270 & 7.16 & 2.078 \\
\hline 7 & 3 & $25,24,24$ & 130 & 270 & 4.26 & 6.896 \\
\hline 8 & 2 & 31,25 & 130 & 200 & 1.31 & 14.826 \\
\hline 9 & 3 & $23,22,17$ & 130 & 200 & 2.12 & 7.521 \\
\hline 10 & 3 & $14,23,21$ & 130 & 200 & 1.55 & 8.011 \\
\hline 11 & 3 & $19,17,28$ & 130 & 200 & 2.41 & 7.287 \\
\hline 12 & 3 & $27,16,22$ & 130 & 200 & 3.59 & 5.011 \\
\hline 13 & 3 & $20,28,16$ & 130 & 200 & 2.16 & 8.164 \\
\hline 14 & 3 & $28,20,22$ & 130 & 200 & 3.04 & 6.719 \\
\hline 15 & 4 & $19,16,14,20$ & 130 & 200 & 2.52 & 5.947 \\
\hline 16 & 2 & 32,20 & 130 & 200 & 1.51 & 11.549 \\
\hline 17 & 4 & $16,18,17,24$ & 130 & 200 & 2.21 & 8.095 \\
\hline 18 & 4 & $17,16,17,16$ & 130 & 200 & 3.33 & 4.071 \\
\hline 19 & 3 & $32,27,26$ & 130 & 200 & 6.72 & 4.426 \\
\hline 20 & 5 & $20,25,24,23,20$ & 130 & 200 & 9.67 & 15.094 \\
\hline 21 & 4 & $26,19,19,21$ & 130 & 200 & 6.18 & 21.285 \\
\hline 22 & 3 & $24,26,24$ & 130 & 50 & 4.91 & 9.818 \\
\hline 23 & 4 & $17,23,19,20$ & 130 & 200 & 3.44 & 16.060 \\
\hline 24 & 4 & $29,24,17,20$ & 130 & 200 & 10.13 & 3.434 \\
\hline 25 & 3 & $23,32,26$ & 130 & 200 & 8.11 & 8.611 \\
\hline 26 & 4 & $28,12,25,11,13$ & 130 & 200 & 7.52 & 5.345 \\
\hline 27 & 3 & $24,24,21$ & 130 & 200 & 9.59 & 3.695 \\
\hline \multirow[t]{3}{*}{28} & 3 & $27,28,15$ & 130 & 200 & 9.4 & 3.734 \\
\hline & & Jumlah/Total & & & 128.56 & 196.922 \\
\hline & & Rata-rata/Mean & & & 4.6 & 7.033 \\
\hline
\end{tabular}

\section{B. Analisis Biaya}

Dengan memperhitungkan biaya pembangunan perlengkapan GSS beserta kabel dan perlengkapan lainnya sebesar Rp 40 juta maka dapat dapat dihitung biaya operasi dengan hasil disajikan pada Tabel 2. 
Tabel 2. Biaya tetap dan tidak tetap mesin modifikasi Expo-2000

Table 2. Fixed and variable cost of modified Expo-2000

\begin{tabular}{|l|r|l|r|}
\hline \multicolumn{1}{|c|}{$\begin{array}{c}\text { A. Biaya tetap } \\
\text { (fixed cost) }\end{array}$} & No & Biaya-biaya (cost of) & $\begin{array}{c}\text { Rp/jam } \\
\text { (Rp/hour) }\end{array}$ \\
\hline & 1 & Biaya penyusutan (Depreciation) & 3,600 \\
\hline & 2 & Bunga modal (Interest rate) & 2,160 \\
\hline & 3 & Biaya pajak (Tax) & 240 \\
\hline & 3 & Biaya asuransi (Insurance) & 360 \\
\hline & & Jumlah (Total) A & 6,360 \\
\hline $\begin{array}{l}\text { B. Biaya variable } \\
\text { (Variable cost) }\end{array}$ & 1 & Operator mesin (Operator) & 9,375 \\
\hline & 2 & Upah tenaga kerja pembantu (Labour) & 17,500 \\
\hline & 3 & Biaya bahan bakar (Fuel) & 5,000 \\
\hline & 4 & Oli dan pelumas (Grease and oil) & 100 \\
\hline & 5 & Biaya perawatan (Maintenance) & 2,000 \\
\hline & & Jumlah (Total) B & 33,975 \\
\hline & & & $\begin{array}{l}\text { Pemasangan dan bongkar jalur kabel } \\
\text { (Setting and sett-of cable line) }\end{array}$ \\
\hline $\begin{array}{l}\text { C. Biaya persiapan } \\
\text { Preparation cost) }\end{array}$ & & Jumlah (Total) A + B + C & 8.333 \\
\hline & & 48.668 \\
\hline
\end{tabular}

Catatan : Penggunaan bahan bakar solar \pm 1 liter / jam. Harga setempat adalah Rp 5.000/liter.

Notes : Fuel used of gasoline \pm 1 litre / hour. Localprice was Rp 5000/ litre

Dari Tabel 2 diketahui seluruh biaya pengeluaran sebesar Rp 48.668/jam yang terbagi atas biaya tetap sebesar Rp 6.360/jam dan biaya tidak tetap sebesar Rp 33.975/jam dan biaya persiapan, pemasangan serta bongkar sebesar Rp 8.333/jam. Dengan produktivitas pengumpulan kayu sebanyak 7,033 $\mathrm{m}^{3} / \mathrm{jam}$, maka dapat dihitung biaya pengeluaan kayu per $\mathrm{m}^{3}$ adalah sebesar Rp 6.920. Biaya ini cukup murah dibanding biaya pikul manual sebesar Rp 30-100 ribu, tergantung jarak dan tingkat kesulitan. Sedangkan produktivitas dengan cara manual relatif rendah yakni sekitar $0,3-1,0 \mathrm{~m}^{3}$ per jam. Dengan kondisi seperti itu maka dapat dikatakan penggunaan prototipe modifikasi Exp-2000 cukup efektif dan efisien.

Dari analisis finansial berikut ini (Tabel 3) dapat diketahui bahwa untuk pengeluaran kayu menggunakan metode GSS dan dengan memberikan harga sewa Rp $11.000 / \mathrm{m}^{3} / \mathrm{hm}$ maka nilai NPV diperoleh sebesar Rp 8.333.560 sedang IRR sebesar 31,9\%. Dari besaran tersebut diyakini peralatan itu masih dapat memberikan nilai ekonomis untuk diusahakan, apalagi kini harga-harga kayu terus melambung sehingga logis bila pemafaatan sumberdaya alam hutan dilakukan dengan seefektif dan seefisien mungkin. 
Tabel 3. Analisis NPV dan IRR dari ketiga pelengkap alat GSS

Table 3. Analysis of NPV and IRR of three completion of GSS

\begin{tabular}{|c|c|c|c|c|c|}
\hline \multicolumn{6}{|c|}{$\begin{array}{l}\text { Jam kerja } 8 \text { jam hari kerja } 150 \text { hari dengan harga } \mathrm{Rp} 10500 / \mathrm{m}^{3} \\
\text { (Working hour } 8 \text { bours/ day of } 150 \text { days/year and rental fee of about } \mathrm{Rp} 10.500 / \mathrm{m}^{3} \text { ) }\end{array}$} \\
\hline $\begin{array}{l}\text { Tahun } \\
\text { (year) }\end{array}$ & $\begin{array}{c}\text { Biaya } \\
\text { investasi } \\
\text { (Capital } \\
\text { invest })\end{array}$ & $\begin{array}{c}\text { Biaya } \\
\text { operasi } \\
\text { (Operating } \\
\text { cost) }\end{array}$ & $\begin{array}{l}\text { Pendapatan } \\
\text { (Income) }\end{array}$ & $\begin{array}{l}\text { Pendapatan } \\
\text { bersih } \\
\text { (Net cash } \\
\text { inflow) }\end{array}$ & $\begin{array}{l}\text { Nilai saat ini } \\
\text { (Present value) }\end{array}$ \\
\hline 0 & $(20,000,000)$ & & & $20,000,000$ & $(20,000,000)$ \\
\hline 1 & & $86,241,760$ & $88,615,800$ & $2,374,040$ & $2,011,898$ \\
\hline 2 & & $94,865,936$ & $97,477,380$ & $2,611,444$ & $1,875,498$ \\
\hline 3 & & $104,352,530$ & $107,225,118$ & $2,872,588$ & $1,748,346$ \\
\hline 4 & & $114,787,783$ & $117,947,630$ & $3,159,847$ & $1,629,814$ \\
\hline 5 & & $126,266,561$ & $129,742,393$ & $3,475,832$ & $1,519,318$ \\
\hline \multirow[t]{4}{*}{6} & & $138,893,217$ & $142,716,632$ & $3,823,415$ & $1,416,314$ \\
\hline & & & & NVP & $-9,798,811$ \\
\hline & & & & IRR & \#NUM! \\
\hline & & & & & \\
\hline \multicolumn{6}{|c|}{$\begin{array}{l}\text { Jam kerja } 8 \text { jam hari kerja } 150 \text { hari dengan harga } \mathrm{Rp} 11.000 / \mathrm{m}^{3} \\
\text { (Working hour } 8 \text { bours/day of } 150 \text { days/year and rental fee of about } \mathrm{R} p 11.000 / \mathrm{m}^{3} \text { ) }\end{array}$} \\
\hline $\begin{array}{c}\text { Tahun } \\
\text { (year) }\end{array}$ & $\begin{array}{c}\text { Biaya } \\
\text { investasi } \\
\text { (Capital } \\
\text { invest) }\end{array}$ & $\begin{array}{c}\text { Biaya } \\
\text { operasi } \\
\text { (Operating } \\
\text { cost) }\end{array}$ & $\begin{array}{l}\text { Pendapatan } \\
\text { (Income) }\end{array}$ & $\begin{array}{c}\text { Pendapatan } \\
\text { bersih } \\
\text { (Net cash } \\
\text { inflow) }\end{array}$ & $\begin{array}{l}\text { Nilai saat ini } \\
\text { (Present value) }\end{array}$ \\
\hline 0 & $(20,000,000)$ & & & $(20,000,000)$ & $(20,000,000)$ \\
\hline 1 & & $86,241,760$ & $92,835,600$ & $6,593,840$ & $5,588,000$ \\
\hline 2 & & $94,865,936$ & $102,119,160$ & $7,253,224$ & $5,209,153$ \\
\hline 3 & & $104,352,530$ & $112,331,076$ & $7,978,546$ & $4,855,990$ \\
\hline 4 & & $114,787,783$ & $123,564,184$ & $8,776,401$ & $4,526,770$ \\
\hline 5 & & $126,266,561$ & $135,920,602$ & $9,654,041$ & $4,219,870$ \\
\hline \multirow[t]{3}{*}{6} & & $138,893,217$ & $149,512,662$ & $10,619,445$ & $3,933,777$ \\
\hline & & & & NVP & $8,333,560$ \\
\hline & & & & IRR & 0.3185 \\
\hline
\end{tabular}




\section{Pembahasan}

Dari kajian sebelumnya diketahui bahwa peningkatan produktivitas kerja mencapai hampir 3,5 kalinya. Adanya peningkatan ini di antaranya disebabkan oleh adanya perbaikan pada kereta angkut kayu yang pada sebelumnya menggunakan pengunci model baud, sementara pada kereta angkutan kayu yang baru menggunakan sistem kito. Pada sistem baud kelemahannya yakni ulir cepat aus sehingga mengakibatkan slack sehingga kereta kayu tidak dapat dikunci pada kabel tanpa ujung. Pada sistem kito ini di samping proses pengunciannya lebih sederhana, juga lebih tahan lama karena penguncian kabel terjadi akibat jepitan gaya berat beban.

Berdasarkan analisis sederhana dapat dikatakan bahwa apabila alat serupa bisa dibangun oleh masyarakat atau dapat disediakan oleh setiap unit KPH yang di wilayahnya memiliki areal kerja menuju petak tebangan sulit diakses karena jurang, sungai, medan curam, dan tenaga kerja susah, serta jalan sempit, maka dengan bantuan alat teknologi kabel layang gaya gravitasi yang cukup murah harganya, diyakini cukup produktif untuk membantu dalam pengeluaran kayu.

Dengan demikian untuk memenuhi kebutuhan industri pengolahan kayu dapat segera dipasok dengan lancar dengan penghematan biaya cukup besar. Sebagai gambaran berdasarkan pengalaman tahun 2005 lalu, pada lapangan yang sangat sulit perusahaan pembeli kayu berani memberikan upah pengeluaran kayu hingga Rp $100 \mathrm{ribu} / \mathrm{m}^{3}$ agar kayu dari petak tebangan segera dapat terangkut keluar. Dengan pengeluaran upah sebesar itu penggunaan GSS tentu dapat menghemat pembiayaan. Kelemahan dalam pengeluaran kayu dengan sistem GSS ini ialah proses untuk dapat dikumpulkan mendekati ke tempat peluncuran agak lambat karena kemampuan pemikulan amat terbatas.

Untuk masalah pembiayaan, khususnya pada pengitungan biaya tetap, pada Yuta (1954) dinyatakan bahwa biaya tetap untuk tip-tiap jam, umumnya terdiriatas:

1. Biaya sebagai akibat pengurangan harga (penghapusan) biasanya ditetapkan menurut cara lurus (straight line).

2. Biaya bunga (average interest)

3. Biaya untuk pajak, asuransi dan penimbunan.

4. Biaya overhead (untuk organisasi, dan lain-lain)

5. Biaya untuk revisi seluruhnya yang dilakukan satu kali tiap-tiap tahun (majoroverhaul)

6. Supir.

Selain itu umur mesin dan dasar bunga adalah faktor yang sukar ditaksir. Lebih pendek umur mesin selama biaya investasi yang harus dihapuskan, lebih ringan risikonya, tetapi lebih tingggi pula biaya penghapusan. Sebaliknya lebih lama jangka waktu penghapusan lebih rendah biaya-biaya tetapi lebih besar pula risikonya yang disebabkan karena mesin menjadi aus atau tak dapat dipakai lagi. Selain itu dasar bunga sukar sekali ditetapkan secara obyektif. Lebih besar bunga lebih tinggi pula harga pokok dan penjualan maupun laba bilamana harga jual diterima. Di Amerika Serikat pengusaha swasta memakai bagan sebesar 10\% yang terdiri dari (a) bunga 6\%; (b) pajak 2\%; (c) asuransi 1\%; (d) penimbunan 1\% (Yuta (1954).

Menurut Reynolds dalam Yuta (1954) untuk perhitungan biaya dari harga-harga investasi untuk gergaji rantai, traktor dan truk bunganya dihitung sebesar $7 \%$, sedangkan Matthews sebesar 10\%, dan untuk di daerah khatulistiwa dimana resiko yang dihadapi lebih besar maka lebih baik menggunakan angka 15\%. Pada kajian ini bunga ditetapkan 18\% 
dengan pertimbangan resiko moneter yang sering tidak stabil dan juga disesuaikan dengan bunga bank yang berlaku.

Mengenai dampak terhadap lingkungan kenyataan lapangan memperlihatkan cukup jelas bahwa dampak terhadap lapisan permukaan tanah sangat kecil karena kayu melewati jarak dengan cara menggantung di udara. Namun demikian masih ada beberapa hal yang perlu disempurnakan agar operasi pengeluaran kayu dapat dilakukan lebih optimal seperti tercantum pada Tabel 4.

Tabel 4. Hasil evaluasi kinerja penggunaan teknologi kabel layang GSS Table 4. Evaluation results of gravity skyline operation

\begin{tabular}{|l|l|}
\hline No & \multicolumn{1}{|c|}{ Masalah } \\
\hline 1 & $\begin{array}{l}\text { Menyiapkan tiang atau tangga panjat sederhana untuk memudahkan pemasangan } \\
\text { katrol-katrol di pohon (Preparing a simple ladderto set-uppulley on the tree easily) }\end{array}$ \\
\hline 2 & $\begin{array}{l}\text { Memodifikasi kereta angkutan kayu dengan pengunci model gunting (Modifying the } \\
\text { carriage fortransporting log using scissormodel) }\end{array}$ \\
\hline 3 & $\begin{array}{l}\text { Menyiapkan alat bantu pembawa peralatan sederhana untuk memudahkan } \\
\text { pengangkutan (Preparing a simple unit of equipments to make easy in transporting materials) }\end{array}$ \\
\hline 4 & $\begin{array}{l}\text { Menyiapkan sistem komunikasi yang praktis dan mudah dipahami bersama untuk } \\
\text { memudahkan dan memperlancar pengumpulan kayu (Preparing communication system to } \\
\text { makeeasy on gathering of logs) }\end{array}$ \\
\hline 5 & $\begin{array}{l}\text { Menyiapkan media lintas kereta angkut kayu yang dapat dipakai di berbagai kondisi } \\
\text { sehingga saat akan pindah ke jalur kabel lain tidak perlu harus menurun naikan muatan } \\
\text { (Preparing a remover of carriage that can be used for changing the rail way to other direction and can be } \\
\text { usedforany condition) }\end{array}$ \\
\hline
\end{tabular}

Dari Tabel 4 dapat diketahui bahwa masih diperlukan beberapa penyempurnaan lebih lanjut terutama alat pendukungnya agar kegiatan pengeluaran kayu lebih lancar dimulai sejak pemilihan lokasi jalur dan setting kabel (pasang, bongkar dan menggulungnya kembali ke dalam drum). Alat tersebut antara lain berupa tangga panjat pohon yang mudah dipindah dan dibawa di lapangan.

\section{KESIMPULAN DAN SARAN}

1. Pengeluaran kayu sistem kabel gaya berat (GSS) dengan menggunakan kereta pengangkut kayu system pengunci kito merupakan metode yang cukup efektif dan efisien.

2. Produktivitas pengumpulan kayu dengan GSS rata-rata $7,033 \mathrm{~m}^{3} . \mathrm{hm} / \mathrm{jam}$.

3. Dari analisis finansial diketahui dengan modal untuk membangun seperangkat peralatan pengeluaran kayu seharga Rp 20 juta diperoleh hasil NPV Rp 8.333.560 dan IRR sebesar $31,9 \%$.

4. Berdasarkan kajian ini penggunaan teknologi kabel layang GSS cukup baik dan praktis untuk dapat digunakan dalam mengeluarkan kayu dan murah khususnya pada daerahdaerah sulit. 


\section{DAFTAR PUSTAKA}

Anonim. 1993. Statistik tahunan. Kanwil Departemen Kehutanan Propinsi Jawa Barat.

Basari, Z. 2002. Produktivitas pengeluaran dolok kayu tusam dengan sistem kabel layang Iwafuji 115. Buletin Penelitian Hasil Hutan 1 (20) : 20-34. Pusat penelitian dan Pengembangan Teknologi Hasil Hutan. Bogor.

Basari, Z; Wesman E. dan Marolop S. 1998. Ekstraksi kayu dengan sistem kabel layang gaya berat ver rem di areal hutan tusam KPH Pekalongan Barat Perum Perhutani Jawa Tengah. Buletin Penelitian Hasil Hutan 6 (15) : 371-384. Pusat Penelitian dan Pengembangan Hasil Hutan dan Sosial Ekonomi Kehutanan. Bogor.

Dulsalam. 2006. Pengeluaran kayu dengan sistem kabel layang di hutan rakyat. Naskah Seminar Hasil Hutan.

Yuta, E.H.P. 1954. Pemungutan Hasil Hutan. Timun Mas N.V. Jakarta. 
Lampiran (Appendix)

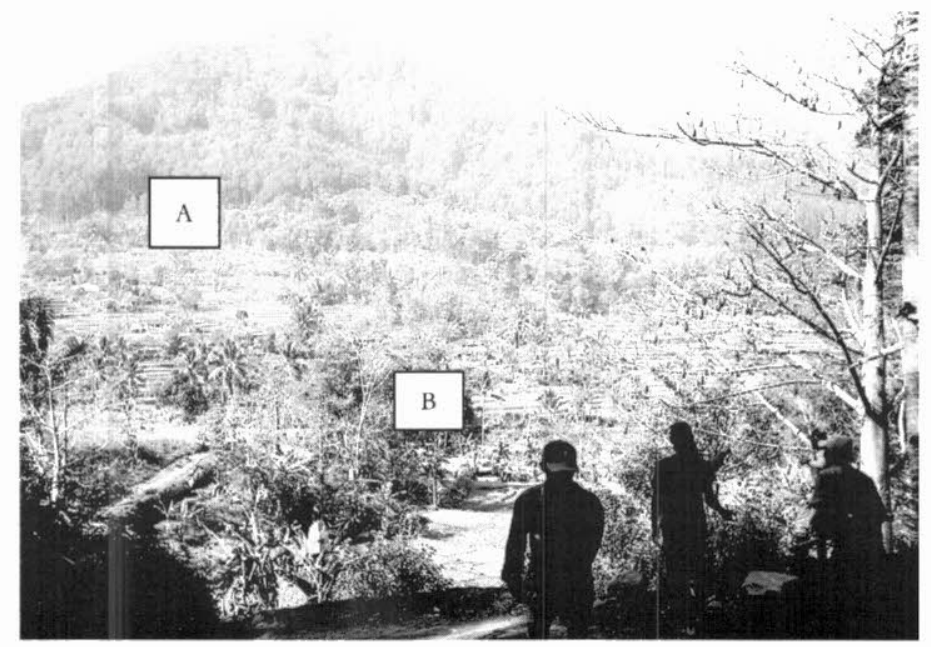

Gambar1. Pemandangan lokasi uji coba pengeluaran kayu pinus , $A=$ tempat alat GSS, B = tempat penurunan kayu

Figure 1. A view of study area on wood extraction, $A=$ the unit of GSS located, $B=$ Location for unloaded of extraction wood.
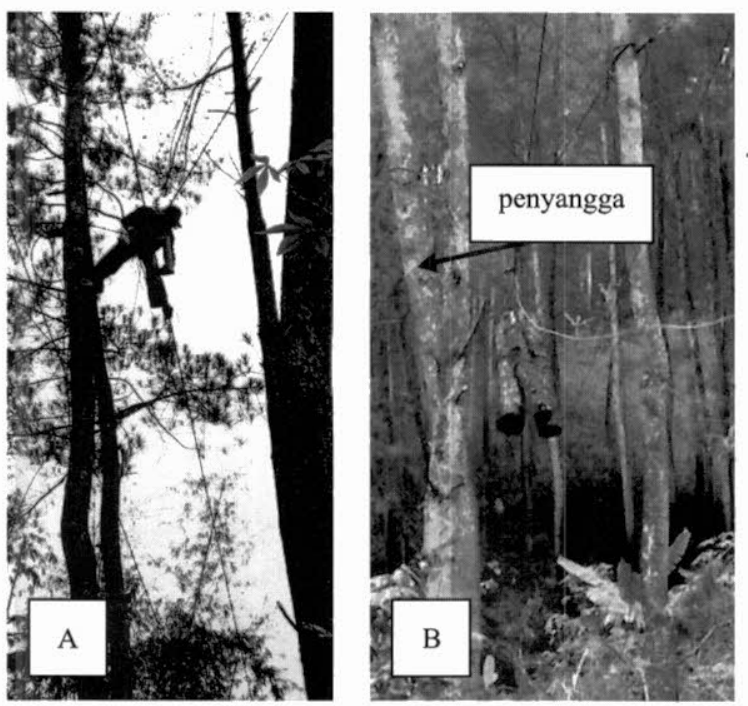

Gambar 2. Penggunaan penyangga (A), saat pemasangan penyangga (B) kayu dapat menggantung cukup tinggi di udara

Figure 2. The usage of support tree, $A=$ setting of support tree, $B=$ Log hanging at the air at ascertain beight. 

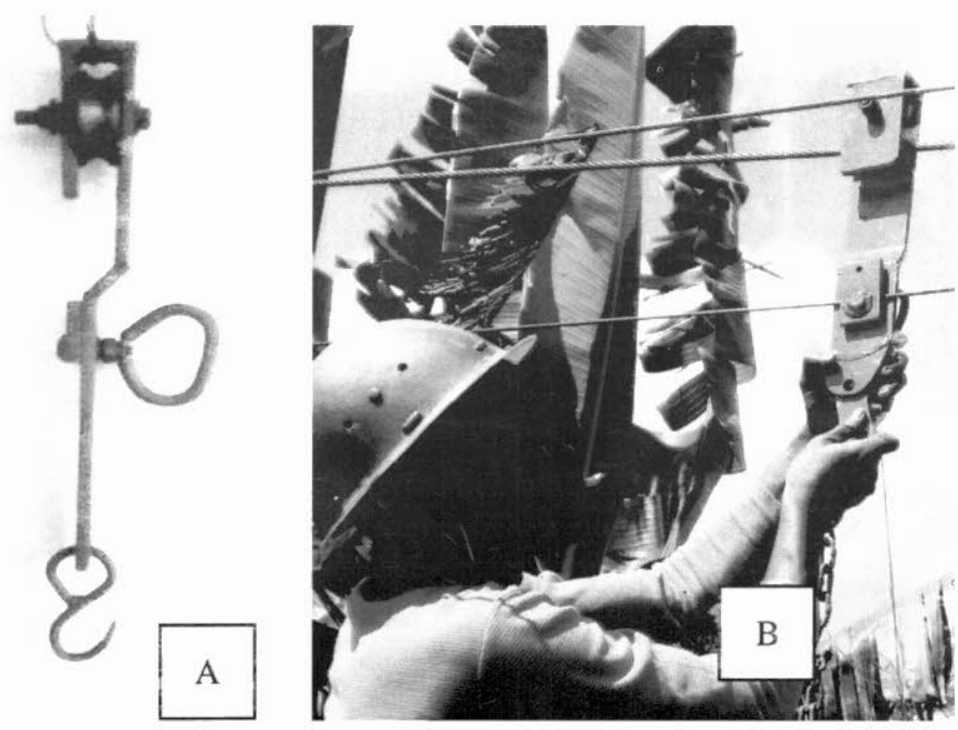

Gambar3. Kereta angkut kayu model lama yang dipakai dalam pengeluaran kayu (A) dan kereta angkut kayu yang diperbaiki model kito (B)

Figure 3. Carriage for log transpot in the air of old version (A) and new carriage that improved using kito model (B). 